OPEN ACCESS

Edited by:

Shiv K. Gupta,

Mayo Clinic, United States

Reviewed by:

Thomas Daubon

Institut National de la Santé et de la

Recherche Médicale (INSERM).

France

Robin T. Varghese,

Edward Via College of Osteopathic

Medicine, United States

${ }^{*}$ Correspondence:

Drazen Raucher

draucher@umc.edu

Specialty section: This article was submitted to Cancer Molecular Targets and Therapeutics,

a section of the journal Frontiers in Oncology

Received: 09 October 2018 Accepted: 03 December 2018 Published: 17 December 2018

Citation:

Raucher D, Dragojevic S and Ryu J (2018) Macromolecular Drug Carriers for Targeted Glioblastoma Therapy: Preclinical Studies, Challenges, and

Future Perspectives. Front. Oncol. 8:624. doi: 10.3389/fonc.2018.00624

\section{Macromolecular Drug Carriers for Targeted Glioblastoma Therapy: Preclinical Studies, Challenges, and Future Perspectives}

\author{
Drazen Raucher*, Sonja Dragojevic and Jungsu Ryu \\ Department of Cell and Molecular Biology, University of Mississippi Medical Center, Jackson, MS, United States
}

Glioblastoma, the most common, aggressive brain tumor, ranks among the least curable cancers-owing to its strong tendency for intracranial dissemination, high proliferation potential, and inherent tumor resistance to radiation and chemotherapy. Current glioblastoma treatment strategies are further hampered by a critical challenge: adverse, non-specific treatment effects in normal tissue combined with the inability of drugs to penetrate the blood brain barrier and reach the tumor microenvironment. Thus, the creation of effective therapies for glioblastoma requires development of targeted drug-delivery systems that increase accumulation of the drug in the tumor tissue while minimizing systemic toxicity in healthy tissues. As demonstrated in various preclinical glioblastoma models, macromolecular drug carriers have the potential to improve delivery of small molecule drugs, therapeutic peptides, proteins, and genes to brain tumors. Currently used macromolecular drug delivery systems, such as liposomes and polymers, passively target solid tumors, including glioblastoma, by capitalizing on abnormalities of the tumor vasculature, its lack of lymphatic drainage, and the enhanced permeation and retention (EPR) effect. In addition to passive targeting, active targeting approaches include the incorporation of various ligands on the surface of macromolecules that bind to cell surface receptors expressed on specific cancer cells. Active targeting approaches also utilize stimulus responsive macromolecules which further improve tumor accumulation by triggering changes in the physical properties of the macromolecular carrier. The stimulus can be an intrinsic property of the tumor tissue, such as low pH, or extrinsic, such as local application of ultrasound or heat. This review article explores current preclinical studies and future perspectives of targeted drug delivery to glioblastoma by macromolecular carrier systems, including polymeric micelles, nanoparticles, and biopolymers. We highlight key aspects of the design of diverse macromolecular drug delivery systems through a review of their preclinical applications in various glioblastoma animal models. We also review the principles and advantages of passive and active targeting based on various macromolecular carriers. Additionally, we discuss the potential disadvantages that may prevent clinical application of these carriers in targeting glioblastoma, as well as approaches to overcoming these obstacles.

Keywords: macromolecular, glioblasoma, preclinic study, drug carriers, targeted therapies 


\section{INTRODUCTION}

Glioblastoma (GBM) is the most common and the most aggressive primary malignant tumor of the central nervous system. Current therapy regimens are initial surgical resection which is followed by radiation and chemotherapy using the DNA alkylating agent Temozolomide. However, glioblastoma tumors are very aggressive and resistant to multimodal therapies, and the average life expectancy and overall survival is $<18$ months. Therefore, current clinical therapies are ineffective as they are more palliative in nature than curative. Treatment options are limited since complete surgical resection is impossible and since tumor tissue is heterogeneous and penetrates surrounding healthy brain tissue. As a result, almost all the patients develop recurrent tumors, which are more aggressive and often resistant to anticancer drugs. Furthermore, drug delivery to the brain is hampered by the presence of blood brain barrier (BBB) (Figure 1), resulting in poor delivery of drugs to the tumor tissue and dose related systemic toxicity in healthy tissues. Considering limitations and overall ineffectiveness of the current approaches in the treatment of glioblastoma, there is an urgent need for more efficient treatments to achieve improved outcome and increase overall survival in glioblastoma patients.

One of the approaches of tumor specific drug delivery is based on macromolecular drug carriers. Advantages of macromolecular carriers over small molecule drugs include protection of the drugs from degradation, improvement of drug solubility, and blood plasma half-life-time, release of the drugs in the optimal dosage range, and delivery of the anticancer agents specifically to the tumor. Currently used macromolecular drug delivery systems, such as liposomes and polymers, passively target solid tumors by capitalizing on abnormalities of the tumor vasculature, its lack of lymphatic drainage, and the enhanced permeation and retention (EPR) effect. However, to achieve therapeutic efficacy in treating GBM, polymeric carriers must successfully overcome several transport barriers (including $\mathrm{BBB}$ ), extravasate tumor micro vessel walls, and penetrate the plasma membrane of the tumor cells. In addition to passive targeting, further selectivity of macromolecules can be achieved by active targeting. Active targeting approaches include the application of cancer biomarker proteins that bind to overexpressed cell surface proteins in specific cancer cells. It also includes stimuli-responsive macromolecular carriers which can release anticancer drugs specifically in the tumor tissue or tumor cells in response to internal or external stimuli. Internal stimuli drug release is based on the fact that tumor tissue has a different environment compared to normal tissue; more acidic $\mathrm{pH}$, higher redox potential, and/or overexpressed proteins, and enzymes. In addition, stimuli such as light, ultrasound, a magnetic field, and temperature, can be also applied to the tumor site externally to allow drug to be released and their molecular target in the cancer cells reached.

In the present review, we report the use of macromolecular carriers with different composition, including lipids, proteins, and synthetic nanoparticles and we consider their targeting aspects. We also review selected preclinical brain drug delivery macromolecular carriers and highlight their potential in the clinical treatment of glioblastoma.

\section{ACTIVE TARGETING}

Active targeting to tumor sites generally exploits an intrinsic cell characteristic to obtain drug delivery. Utilizing a homing device such as an antibody or ligand, a drug can bind tumor cells through antigens or receptors without affecting any other normal tissues (1).

This classic concept of active targeting has been successful due to its high selectivity and binding affinity to produce a series of antibody-drug conjugates or ADC. Currently, there are several marketed ADC including Brentuximab and Trastuzumab; however, much more promising ADC are under investigation in clinical trials (2). Despite all of the enthusiasm toward this type of approach, ADC strategy is also facing a few problems that must be resolved in order to take a greater step forward. These problems include low efficiency in cellular uptake or in endosomal escape, heterogeneity of tumor cells in the expression of specific receptors, and challenges in manufacturing (3).

Another example of active targeting is stimuli-responsive targeting. As knowledge of tumor biology and technologies advances, a variety of novel, and smart devices have been introduced showing unprecedented efficiency of drug delivery. Environmentally responsive macromolecular drug carriers can release cargo drugs in the targeted tumor tissues as a response of external stimuli such as heat, light, ultrasound, and a magnetic field. This triggered drug release provides advantages over other types of active targeting technologies in that it allows exquisite control over time and location of drug release (4).

\section{Receptor-Mediated Endocytosis}

Clathrin-dependent endocytosis is known for a predominant mechanism for the internalization of ADC even though the other pathways including caveolin-mediated, clathrin-caveolinindependent, and cholesterol/macropinocytosis-mediated are also reported in literature (5). To briefly describe this process, once binding to specific receptor, ADC-receptors are invaginated by cells through the formation of clathrin-coated vesicles. With dynamin GTPase, the vesicles are then released from the membrane with some of the mature vesicles fusing with lysosomes to form lysosome-late-endosome hybrids through Ras-related protein 7 (Rab7). While cells perform this whole procedure for acceptance of the ADC-receptors, ADC have a couple of opportunities to release drugs from the antibody. First, ADC can release drugs in the endosomal phase. Acid-labile linkers such as (6-maleimidocaproyl) hydrazine $(\mathrm{EMCH})$ allow ADC to unload drugs in the endosome because of the acidic environment of endosomes. Second, ADC can release drug in the lysosome. The high content of enzymes such as cathepsins and collagenases in lysosomes can digest some dipeptide linkers such as valine-citrulline (vc) or phenylalanine-lysine linkers which are specific for cathepsin B. Third, even without a cleavable linker between antibody and drug, drugs can be released by proteolytic digestion in the lysosome. Some products from the digestion of metabolites 


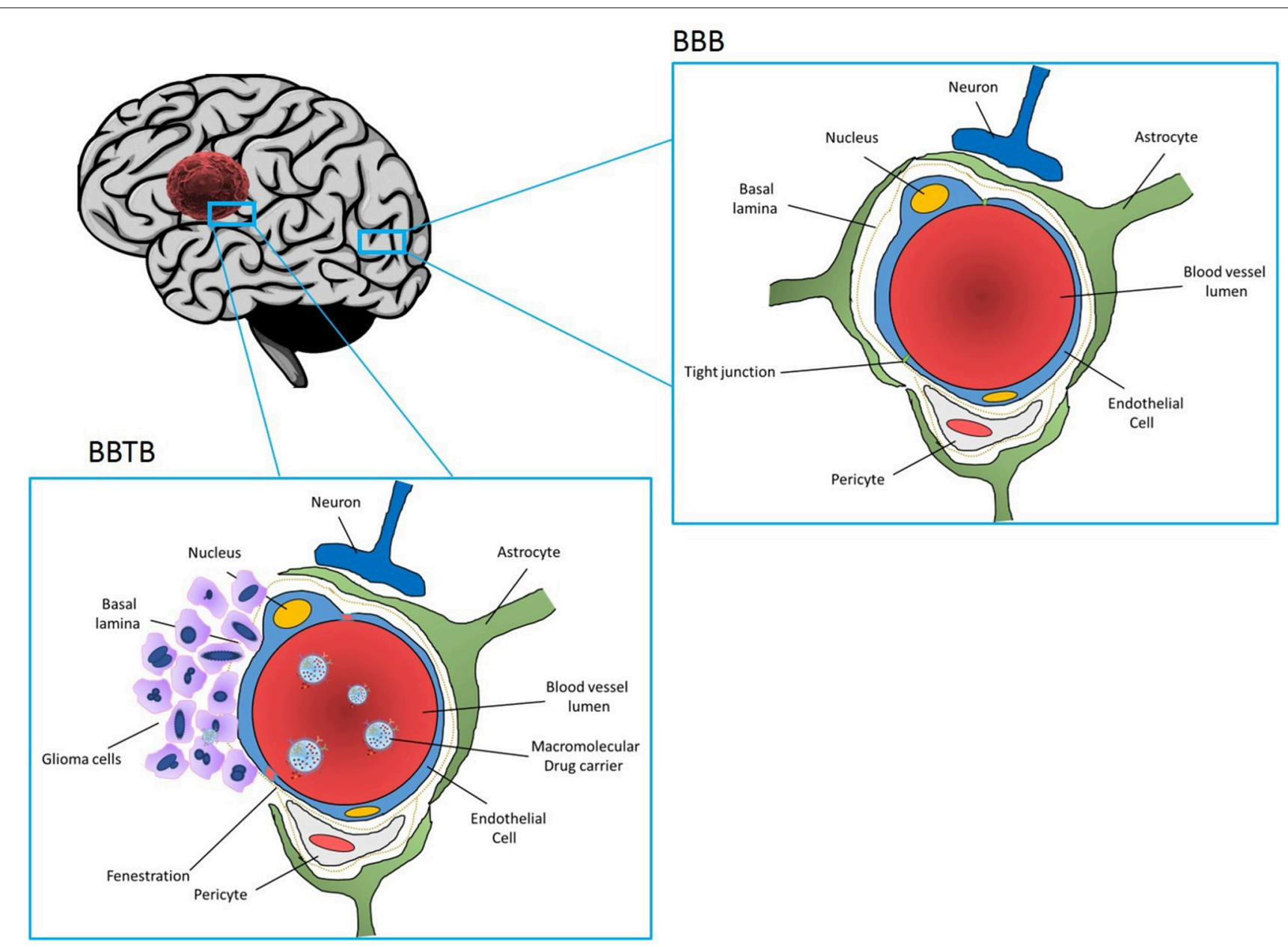

FIGURE 1 | Section of the brain showing normal part of the brain and blood brain barrier (BBB) (upper figure), and part of the brain infiltrated with GBM Blood vessels are enclosed by endothelial cells connected with tight junctions which seal the intercellular space and prevent entrance of drugs from the blood stream to the brain. BBB is further reinforced with a basal lamina. While basal lamina is disrupted by GBM tumor cells (figure the left), endothelial cells are still present forming blood brain tumor barrier (BBTB). Nanoparticles loaded with drugs and coated with receptors specific to the tumor vasculature and glioma cells can interact with the BBTB allowing for transcytosis and delivery of the drugs to GBM tumor cells.

still retain the original activities of the drug and express their activities in the cells or neighboring cells; thebystander effect (6).

Another mechanism involved in internalization of ADCreceptor is autophagy. As a part of the autophagy process, ADCreceptor can be taken up by autophagosomes and digested in autolysosomes releasing drugs afterward (7).

\section{Antibodies}

\section{Epidermal Growth Factor Receptor EGFR}

The most common genetic aberration associated with malignant glioma is amplification of the epidermal growth factor receptor, with a frequency of about $50 \%$ (8).

Targeting the receptor for epidermal growth factor receptor (EGFR) has been rewarding in cancer and many pharmaceuticals are approved alone or in combination with chemotherapy for colorectal cancer, non-small-cell lung cancer, and pancreatic cancer, among others, but not for gliomas (9). It remains unresolved why EGFR targeting has not been successful for glioma as it should be ideally suitable in the context of this disease (9).

Jamali et al. delivered curcumin using Poly (D, L-lacticco-glycolic acid) nanoparticles (PLGA NPs). Monoclonal antibody targeting epidermal growth factor receptor variant III (EGFRvIII) was incorporated into PLGA NPs showing selective internalization of the NPs by an EGFRvIII overexpressed human glioblastoma cells and increased photodynamic toxicity of curcumin (10).

In another study, etoposide (ETP) was loaded in solid lipid nanoparticles (SLNs) containing a monoclonal antibody for insulin receptors and another monoclonal antibody against EGFR (11). Since insulin receptors are found on human brain microvascular endothelial cells (HBMEC), these dual targeting nanoparticles passed across HBMEC/HA (human astrocytes), an in vitro model for blood-brain barrier, and increased cytotoxicity in the treatment of U87MG cells (Table 1). 
TABLE 1 | Active targeting with antibodies (or ligands) for GBM treatment.

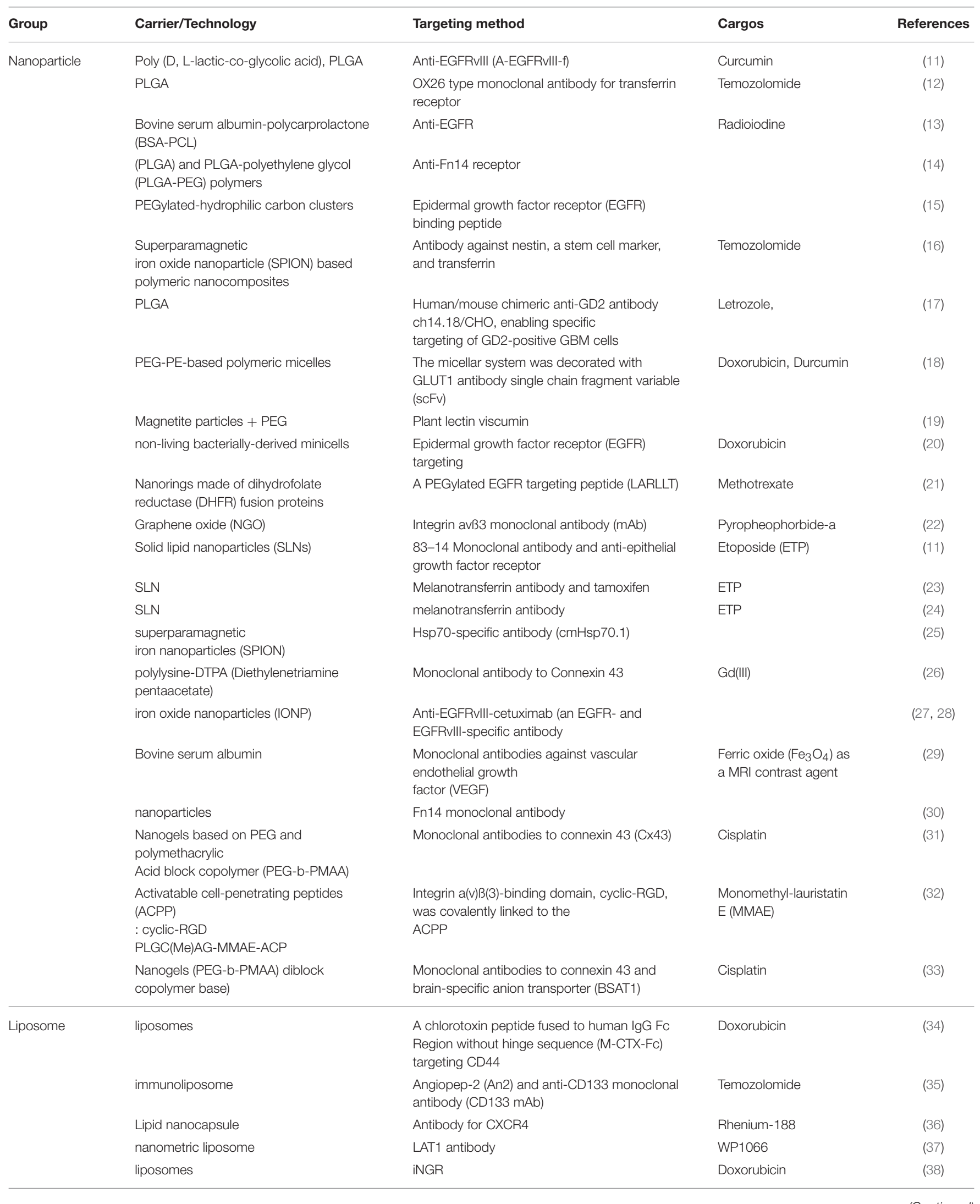


TABLE 1 | Continued

\begin{tabular}{|c|c|c|c|c|}
\hline Group & Carrier/Technology & Targeting method & Cargos & References \\
\hline & PEGylated liposomes & $\begin{array}{l}\text { Anti-VEGF and anti-VEGFR2 monoclonal } \\
\text { antibody }\end{array}$ & Cisplatin & (39) \\
\hline & liposomes & Anti-CD133 monoclonal antibody & $\begin{array}{l}\text { Gemcitabine and } \\
\text { Bevacizumab }\end{array}$ & $(40)$ \\
\hline & a cationic liposome & $\begin{array}{l}\text { Anti-transferrin receptor single-chain antibody } \\
\text { fragments }\end{array}$ & Temozolomide & $(41)$ \\
\hline & PEGylated liposomes & Anti-EGFR & & $(42)$ \\
\hline \multirow[t]{4}{*}{ ADC } & Monoclonal antibody & $\begin{array}{l}\text { The single chain variable fragment (scFv) from } \\
\text { the } \mathrm{D} 2 \mathrm{C} 7 \text { monoclonal } \\
\text { Antibody (mAb) of EGFR }\end{array}$ & $\begin{array}{l}\text { Pseudomonas Exotoxin } \\
\text { PE38KDEL }\end{array}$ & $(43)$ \\
\hline & Monoclonal antibody & $\begin{array}{l}\text { Monoclonal } \\
\text { Antibody against uPARAP/Endo180, }\end{array}$ & $\begin{array}{l}\text { Dolastatin derivative, } \\
\text { monomethyl auristatin } \mathrm{E}\end{array}$ & $(44)$ \\
\hline & Monoclonal antibody & $\begin{array}{l}\text { Anti-CD40 agonistic monoclonal antibody } \\
\text { (FGK45) }\end{array}$ & & $(45)$ \\
\hline & Monoclonal antibody & Glioblastoma-specific CD68 antibody & Curcumin & $(46)$ \\
\hline
\end{tabular}

\section{Transferrin Receptor (TfR)}

TfR plays a key role in the control of the rate of cellular iron uptake, tuning the amount of iron delivered to the metabolic needs of the cells (47).

The presence of $\mathrm{BBB}$ and hard parenchyma of the GBM has been a predominant challenge in chemotherapy in the treatment of GBM. Ever since the finding that iron-loaded transferrin is taken up via receptor-mediated endocytosis at the brain capillaries and transcytosed, many researchers have utilized transferring-transferrin receptor to transfer drugs across the $\mathrm{BBB}$ (48).

Kuo et al. also utilized this idea to deliver etoposide for the GBM treatment. They generated solid lipid nanoparticles (SLNs) conjugated with melanotransferrin antibody (MA) and examined its transcytosis efficiency across human brain-microvascular endothelial cells (HBMECs) and the resulting growth inhibition of U87MG cells. The in vitro transwell assay strategy triggered melanotransferrinmediated transcytosis and promoted the growth-inhibitory efficacy in U87MG cells suggesting the MA-ETP-SLNs as a promising delivery system for malignant GBM (24) (Figure 2).

The findings that there is a higher reactivity in GBM for antiTfR and that GBM cells are very sensitive to the effects of anti-TfR mAbs instigated research targeting TfR as a direct way to kill GBM cells rather than a way to bypass BBB (49).

Ramalho et al. developed poly(lactic-co-glycolic acid) nanoparticles functionalized with OX26 type transferrin monoclonal antibody with a purpose to target transferrin receptors on GBM cells (U251 and U87). In this study, the approach facilitated uptake of the nanoparticles by the GBM cells while normal human astrocytes did not internalize the nanoparticles efficiently. However, this encouraging data was not reproduced in comparative cytotoxicity tests with native nanoparticle and TfR-targeting nanoparticle (12).

\section{Antibodies for Cancer Stem Cell}

Cancer stem cells (CSCs), a small population of quiescent or slowly dividing cells, significantly contributes to the resistance to therapy, and recurrence of cancer. Targeting CSCs could be a good strategy to improve the outcome of cancer therapy. There have also been extensive research to cure GBM through targeting specific markers of CSCs such as CD44, aldehyde dehydrogenase (ALDH) and CD133 as follows.

Mahmud et al. fused human IgG Fc of CD44 with a chlorotoxin peptide (M-CTX-Fc). The authors verified the superiority of M-CTX-Fc by comparing U251MG-P1 cells (CD44+) with CD44-negative cells (SKBR3) in cellular uptake, in vitro cytotoxicities and in vivo tumor growth inhibition. Since CD44 positivity represent stemness of a cancer cell line along with other markers such as OCT3/4, SOX2, KLF4, and Nanog, this approach may contribute to the retardation of tumor growth by restricting cancer stem cell population (34).

CD133+/ALDH1+ in glioblastoma stem cells (GSCs) were targeted by Kim et al. to deliver Temozolomide with liposome (35). With additional BBB targeting molecule, angiopep-2 (An2), this dual-targeting immunoliposome encapsulating TMZ (DualLP-TM) increased in vitro cytotoxicity and apoptosis in U87MG GSCs. This approach suggests a potential use of Dual-LP-TMZ as a therapeutic modality for GBM demonstrating significant in vivo tumor reduction in intracranial U87MG-TL GSC xenografts (Table 1).

\section{pH-Responsive Drug Carriers}

One of the most widely used intrinsic stimulus for controlled drug release is $\mathrm{pH}$ difference between normal tissues and tumor tissue, as well as between cellular compartments. Since tumor metabolism is very active and requires considerable energy for tumor growth, there is increased production of hydrogen ions $\left(\mathrm{H}^{+}\right)$and lactate resulting in an acidic tumor environment $(\mathrm{pH} 6.5)(50,51)$. Since normal tissue has a $\mathrm{pH} 7.4$, this difference can then be exploited for triggering drug release 


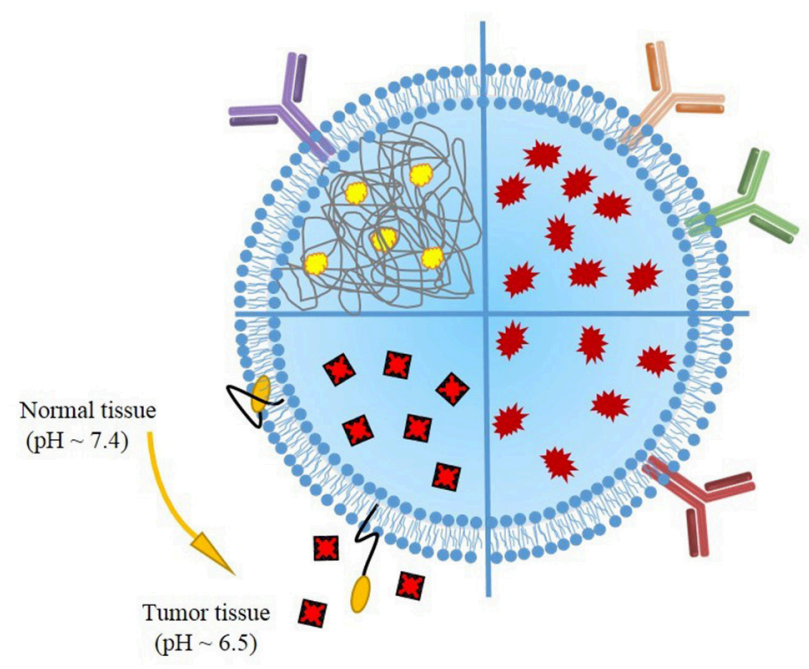

Nanoparticle (liposome)

$\mathrm{Ab}-\mathrm{EGFR} v$ III

PLGA

Organic compound (Curcumin)

$\mathrm{Ab}$ - Insulin receptor
Y

Chemotherapeutic (Etoposide)

$\mathrm{Ab}$ - Melanotransferrin

$\mathrm{pH}$ trigger sequence and cell penetrating peptide

Doxorubicin

FIGURE 2 | Schematic presentation of selected liposomal nanoparticles. Liposomal nanoparticles are versatile, and can be loaded with wide variety of anti-oncogenic compounds, such as curcumin, etoposide, and doxorubicin). To further enhance the targeting, the outer layer includes antibodies targeting GBM cells, or pH responsive and cell penetrating peptides.

in the more acidic tumor tissue. Furthermore, the difference in $\mathrm{pH}$ between cellular compartments at the cellular level, between endosomes ( $\mathrm{pH}$ 5.5) or lysosomes ( $\mathrm{pH} \mathrm{5.0)} \mathrm{can} \mathrm{be} \mathrm{also}$ used to trigger drug release in the cytoplasm. Drug release is usually accomplished by incorporation of an acid sensitive spacer between carrier and drug, which enables drug release at slightly acidic tumor environment or endosomes, and lysosomes of cancer cells.

While these reports use only a $\mathrm{pH}$-triggered drug release mechanism to locally release drug at the tumor site, to further increase specificity Miller at al. (52) constructed a $\mathrm{pH}$-responsive micelle conjugated with a novel moiety against overexpressed cell surface platelet derived growth factor receptor (PDGFR). These micelles are loaded with Temozolomide (TMZ), targeted to PDGFR on glioblastoma cells, resulting in $\mathrm{pH}$-dependent release of TMZ preferably in tumor tissue, thereby reducing systemic toxicity. In vitro studies have shown that these micelles exhibit specific uptake and increased cell killing in glioblastoma cells, and in vivo studies demonstrated increased accumulation of micelles in brain tumor tissues. Although these results are promising, addition of in vivo tumor reduction efficacy and survival experiments would greatly improve the potential of this approach in clinics (Table 2).
An interesting approach to target glioblastoma, reported by Zhao et al. (55) used tumor-specific pH-responsive peptide $\mathrm{H}_{7} \mathrm{~K}\left(\mathrm{R}_{2}\right)_{2}$ as a targeting ligand. This peptide contained the $\mathrm{pH}$ trigger sequence polyhistidine $\mathrm{H}_{7}$ and cell penetrating peptide arginine rich sequence $\left(\mathrm{R}_{2}\right)_{2}$ and exhibited activity at an acidic $\mathrm{pH}$ environment due to the ionization of the histidine thus switching from hydrophobic to hydrophilic conditions. This peptide was used to modify $\mathrm{pH}$-sensitive liposomes loaded with doxorubicin (DOX-PSL- $\mathrm{H}_{7} \mathrm{~K}\left(\mathrm{R}_{2}\right)_{2}$ ). The $\mathrm{pH}$-triggered doxorubicin release from the $\mathrm{pH}$-sensitive liposomes and targeting effect under acidic conditions was demonstrated in in vitro experiments. Furthermore, in vivo experiments in C6 tumor-bearing mice and U87-MG orthotopic tumor-bearing nude mice confirmed the anti-tumor activity of $\mathrm{pH}$-responsive peptide modified liposomes loaded with doxorubicin. Results showed that the DOX-PSL- $\mathrm{H}_{7} \mathrm{~K}\left(\mathrm{R}_{2}\right)_{2}$ (37 days) significantly improved the survival rate of mice compared with control animals (23 days) or doxorubicin treated animals (24 days).

Since doxorubicin is a highly effective anticancer therapeutic for the treatment of many malignancies, there is a great interest in using it in the treatment of glioblastoma. Marrero et al. (53) examined the hydrazine-conjugated doxorubicin 
TABLE 2 | Stimuli responsive targeting macromolecules for GBM treatment.

\begin{tabular}{|c|c|c|c|c|c|c|}
\hline Carrier & Composition & $\begin{array}{l}\text { Targeting } \\
\text { mechanism(s) }\end{array}$ & Drug delivered & Animal model & Outcome & References \\
\hline \multirow[t]{2}{*}{$\begin{array}{l}\text { Polymer } \\
\text { based } \\
\text { carriers }\end{array}$} & Albumin & $\begin{array}{l}\text { (6-maleimidocaproyl) } \\
\text { hydrazone conjugate } \\
\text { of doxorubicin }\end{array}$ & Doxorubicin & $\begin{array}{l}\text { U87-luciferase } \\
\text { expressing } \\
\text { orthotopic } \\
\text { xenografts }\end{array}$ & $\begin{array}{l}\text { Aldoxorubicin, U87-luc tumors were } \\
10 \text {-fold smaller when compared to } \\
\text { control animals, and median } \\
\text { survival of Aldoxorubicin treated } \\
\text { mice was } 62 \text { days, compared to } 26 \\
\text { days median survival of control or } \\
\text { doxorubicin treated animals }\end{array}$ & (53) \\
\hline & Elastin-like polypeptide & Thermo-responsive & $\begin{array}{l}\text { c-Myc inhibitory } \\
\text { peptide }\end{array}$ & $\begin{array}{l}\text { Rat C6 Glioma } \\
\text { orthotopic model }\end{array}$ & $\begin{array}{l}\text { Thermal targeting of the } \\
\text { Bac-ELP1-H1 polypeptide to the } \\
\text { tumors resulted in significant } \\
\text { delayed onset of neurological } \\
\text { deficits, } 80 \% \text { tumor volume } \\
\text { reduction, and doubled survival. }\end{array}$ & (54) \\
\hline Liposomes & $\begin{array}{l}\text { Superparamagnetic } \\
\text { iron oxide }\end{array}$ & Magnetic responsive & Doxorubicin & $\begin{array}{l}\text { Rat C6 glioma } \\
\text { orthotopic model }\end{array}$ & & (56) \\
\hline
\end{tabular}

1,2-distearoyl-sn-glycero-3orthotopic model

phosphocholine;

1,2-Distearoyl-snglycero-

3-phospho-rac-glycerol

sodium salt

Chitosan-PEG copolymer

coated iron oxide

nanoparticles, cross-linked redox responsive

and functionalized with $B G$

Nanoparticles

\section{Poly(ethylene \\ Glycol)-b-poly(trimethylene \\ carbonate-co-dithiolane}

trimeth-ylene carbonate)-b-

polyethylenimine

(PEG-P(TMC-DTC)-PEI,

Human serum albumin (HSA) NPs stabilized with intramolecular disulfide bonds

distearoyl

phosphoethanolamine-

PEG-2000-amine and

$\mathrm{N}$-palmitoyl homocysteine

iron oxide nanoparticles ferumoxytol

poly(ethylene glycol)-poly( $\epsilon$-caprolactone) block copolymer (PEG-PCL)
MMP-14 activatable peptide,

enzyme-responsive

Tumor targeting

peptide angiopep-2

(ANG), redox

responsive

Tumor targeting peptide substance $P$ (SP) redox responsive

Peptide targeting PDGF receptor, $\mathrm{pH}$-responsive

protamine (LMWP)

MMP2/MMP9

activatable peptide, enzyme-responsive
MGMT inhibitor
$0^{6}$-benzylguanine (BG)

Primary GBM6

xenograft tumor

model which

expresses high

levels of MGMT

Protein toxin saporin

U-87 MG-Luc cells orthotopic xenografts

Paclitaxel (PTX)

U-87 MG-Luc cells orthotopic xenografts

Temozolomide (TMZ)

U-87 MG-Luc cells orthotopic xenografts

Azademethylcolchicine

pcGBM39 or pcGBM2- orthotopi xenografts

Paclitaxel (PTX)

C6 glioma cells in Orthotopic xenografts in mice
Treatment with nanoparticles and TMZ showed a 3-fold increase in median overall survival in comparison to TMZ treated and untreated animals.

Treatment with polymersomes resulted in 2-fold increase in median overall survival in comparison untreated animals.

The in vitro PTX release from NPs occurred in a redox-responsive manner. Treatment in vivo showed pro-apoptotic effect and resulted prolonged survival period of treated animals

In vitro studies have shown that micelles have specific uptake and increased cell killing in glioblastoma cells, and in vivo studies reported selective accumulation of micelles in orthotopic glioblastoma model.

In vivo studies demonstrated significant apoptosis of cancer cells and prolonged survival of pcGBM39-bearing mice and complete tumor remission of pcGBM2-bearing mice.

Specific accumulation of PEG-PCL, increased median survival of 48 days when compared to control group (21 days) 
derivative, Aldoxorubicin, which binds selectively to Cysteine34 of blood circulating serum albumin, and releases doxorubicin selectively at the tumor site in response to low $\mathrm{pH}$ tumor environment. Aldoxorubicin-treated mice exhibited high levels of doxorubicin within the tumor tissue, accompanied by apoptosis of glioblastoma cells and a 3-fold decrease in tumor cell proliferation. Effectiveness of Aldoxorubicin treatment was confirmed in in vivo experiments, which demonstrated that when mice were treated with Aldoxorubicin, U87-luc tumors were 10-fold smaller when compared to control animals, or 8-fold smaller when compared with tumors in animals treated with doxorubicin. Importantly, median survival of Aldoxorubicin treated mice was 62 days, compared to 26 days median survival of control and doxorubicin-treated mice. These encouraging results provide a strong rationale to further investigate this approach for the treatment of glioblastoma.

\section{Redox-Responsive Drug Carriers}

Redox-responsive drug delivery carriers exploit the difference in redox potential between the tumor and intracellular environment and normal tissue and blood plasma. Tumor tissues have four times more glutathione (GSH) than normal tissue (62). Furthermore, intracellular concentration of GSH is 3-4 magnitudes higher as compared to the extracellular environment (63). Redox-responsive drug carriers are based on macromolecules containing disulfide bonds which encapsulate drugs. After these redox-responsive carriers are exposed to GSH, disulfide bonds are reduced to sulfhydryl groups resulting in release of encapsulated drugs.

Macromolecular carriers based on different materials, such as proteins, lipids, and polysaccharides have been used as redoxresponsive drug delivery systems to target glioblastoma. For example, Stephen et al. (57) developed superparamagnetic iron oxide nanoparticles coated with cross-linked, redox-responsive chitosan PEG copolymers loaded with $O^{6}$-benzylguanine (BG). The aim of the study was to selectively deliver BG to the glioblastoma in mice, inhibit the DNA repair protein $O^{6}$ methylguanine-DNA methyltransferase (MGMT), and overcome Temozolomide resistance. To further improve tumor targeting, particles were also modified with the tumor-targeting peptide chlorotoxin (CTX). In vitro studies confirmed that BG was released from the particles in the reducing environment, and glioblastoma cells were more responsive to TMZ. In vivo studies, have shown that treatment with such constructed nanoparticles and TMZ showed a 3-fold increase in median overall survival in comparison to TMZ treated and untreated animals.

In another report, Jiang et al. (58) synthesized redoxresponsive virus-mimicking polymersomes (PS) which can efficiently deliver saporin (SAP), a highly potent natural protein toxin, to orthotopic human glioblastoma engrafted in nude mice. To enhance delivery of the drug, polymeromes were modified with angiopep-2 (ANG), a peptide that binds with high affinity to low-density lipoprotein receptor-related protein-1 (LRP-1) which is often overexpressed in glioblastoma cells and brain capillary endothelial cells $(64,65)$. In vivo anti-glioblastoma efficacy experiments have shown that ANG-PS-SAP-treated mice had approximately 7-fold lower tumor bioluminescence intensity than control mice, indicating efficient tumor reduction by ANGPS-SAP. This was confirmed with 2-fold improvement in median survival time from 22 days in control group compared to 43 days in animal treated with ANG-PS- SAP.

A different approach using human serum albumin (HSA) nanoparticles stabilized with intramolecular disulfide bonds and modified by substance P (SP) tumor-targeting peptide to deliver paclitaxel (PTX) to U87 orthotopic xenografts (59). Animals treated with SP-HAS-PTX nanoparticles exhibited antitumoral effect and prolonged survival time of treated mice when compared to control group.

\section{Enzyme-Responsive Drug Carriers}

Enzymes play important roles in all metabolic and biological processes and dysregulation of enzyme activity and expression is exhibited in many diseases including glioblastoma. Therefore, exploiting overexpression of enzymes and their selective catalytic activity as a trigger to release the drug at the tumor site is a very promising approach.

Mohanty et al. (60) applied this concept to deliver the azademethylcolchicine potent active vascular-disrupting agent. They designed an enzyme-responsive carrier consisting of three main elements: (1) theranostic cross-linked iron oxide nanoparticle backbone, (2) matrix metalloproteinase 14 MMP14 cleavable linker, and (3) drug azademethylcolchicine. The iron core of nanoparticles enabled in vivo tracking of the carrier with MRI imaging, which demonstrated significant accumulation of drugs in the glioblastoma tumors in mice.

Treatment with nanoparticles in combination with Temozolomide achieved tumor remission and increased survival pcGBM2-bearing mice by more than 2-fold compared with treatment with temozolomide alone. Thus, this synergistic combination therapeutic strategy may have significant potential for clinical translation to improve long-term outcomes of glioblastoma patients.

Besides MMP-14, some glioblastomas have upregulated MMP-9 and MMP-2. To exploit increased expression of these proteases, $\mathrm{Gu}$ et al. (61) constructed nanoparticles composed of poly(ethylene glycol)-poly( $\epsilon$-caprolactone) block copolymer (PEG-PCL) as the matrix conjugated with activatable cell penetrating peptide protamine (ALWMP, E 10 -PLGLAGVSRRRRRRGGRRRR). Positive charges on the LWMP necessary for transduction were at first masked by a polyanionic peptide (E10) via a MMP-2/9-cleavable peptide linker sequence PLGLAG. Once the nanoparticles were exposed to proteolytic activity of the MMPs, transduction activity of cell penetrating peptides was restored. As a result, these particles loaded with paclitaxel (PTX) exhibited elevated MMP-dependent intracellular accumulation in C6 cells, and improved cytotoxicity. In vivo imaging demonstrated specific accumulation of the particles in intracranial C6 glioma model in nude mice. Specific accumulation of PEG-PCL nanoparticles in glioblastoma was reflected in increased median survival of 48 days when compared to control group (21 days) or taxol (24) alone. These results are promising, and encourage further in vivo experiments in different animal models which would open new modalities for the 
treatment of glioblastoma based on enzyme-responsive targeted drug release.

\section{Magnetic and Ultrasound}

The integrity of the brain is compromised not only by the highly invasive nature of glioblastoma multiforme tumors, but also further exacerbation occurs with standard surgical resection of the tumor. Surgical resection is followed by radiotherapy and chemotherapy, and efficacy of the therapy is monitored by imaging techniques. There are ongoing efforts in clinics to develop approaches to monitor specificity of the therapy and image the tumor at the same time. These tools are called "theranostics", and they integrate imaging and therapeutic modality in the singe macromolecule. Wide application and

A
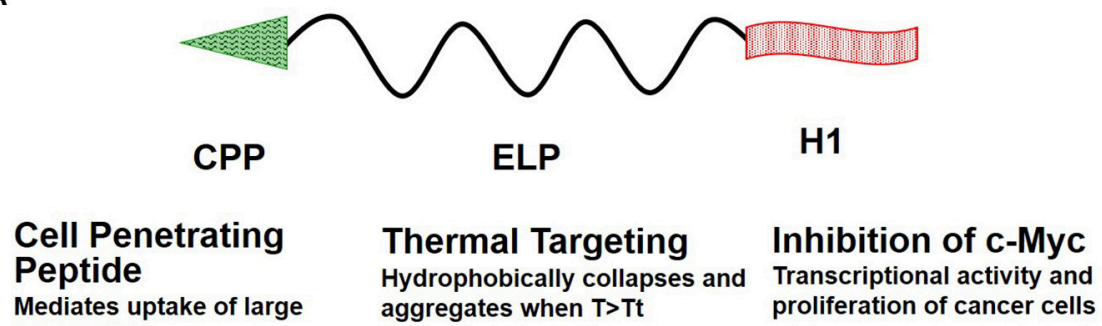
aggregates

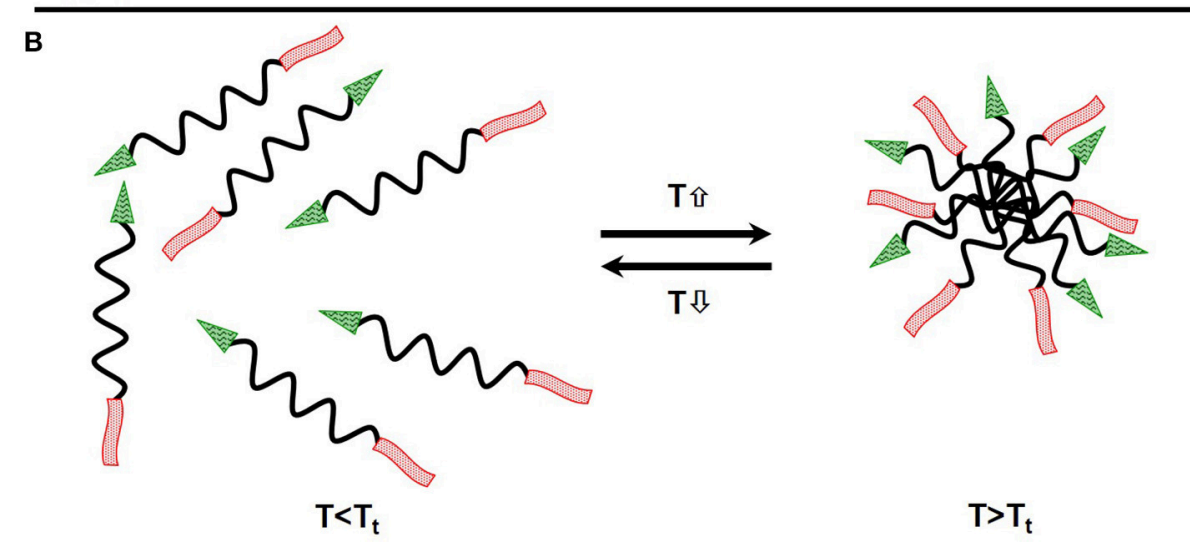

FIGURE 3 | Schematics of the ELP-based drug delivery vector. (A) The delivery system consists of the cell penetrating peptide (CPP) Bac, which promotes cellular uptake of the polypeptide, the thermally responsive elastin-like polypeptide, and a c-Myc transcriptional activity inhibitory peptide ( $\mathrm{H} 1$ ), which inhibits cancer cell proliferation. (B) ELP remains a soluble monomer when the solution temperature is at or below body temperature. When solution temperature is raised above body temperature $T>T_{t}$, it hydrophobically collapses and forms aggregates.

A

\section{Saline}

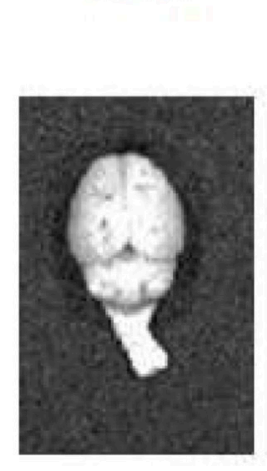

CPP-ELP-H1

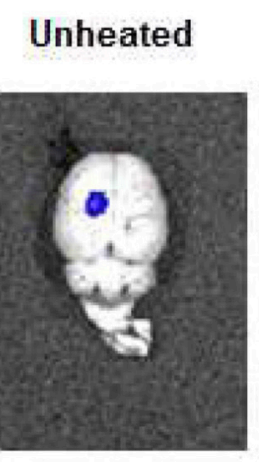

B

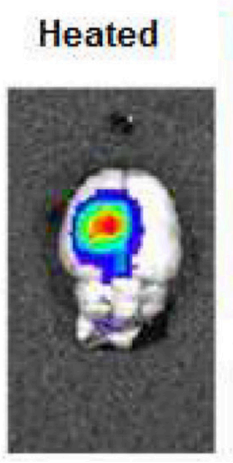

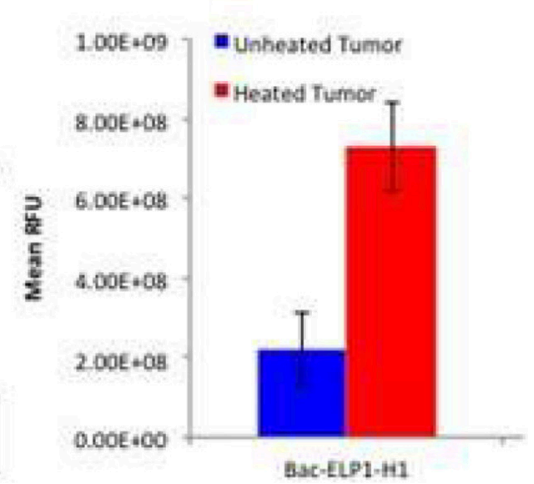

FIGURE 4 | Enhancement of CPP-ELP1-H1 Tumor Uptake by Thermal Targeting. Following IV administration of Alexa750-labeled CPP-ELP1-H1 with or without hyperthermia, construct levels in tumors and organs were determined by ex vivo whole organ fluorescence imaging. (A) Representative brain images from each treatment group. (B) Quantitation of tumor fluorescence from each group. Bars, s.e.m. * Fluorescence levels differ statistically ( $p$, 0.01, one way ANOVA with post-hoc Bonferroni; $n=4$ rats/group). 
versatility of theranostic complexes have led to design and production of various different theranostic compounds.

To use the maximum potential of such theranostic compounds, several groups have included ultrasound in their methodology. Effective drug delivery to the brain tumor is primarily hampered by blood-brain barrier and to overcome $\mathrm{BBB}$, it has been reported that focused ultrasound (FUS) can be used for temporarily opening of the $\operatorname{BBB}(66,67)$. One such approach was used by Fan et al. (56), 2016 for local drug delivery in a rat glioma model. The group has fabricated Superparamagnetic iron oxide (SPIO) conjugated with doxorubicin and embedded in lipid microbubbles (MBs), namely SD-MBs. SD-MBs compounds were used for augmented drug delivery to the brain tumor. The animals underwent FUS sonication after bolus injection of SD-MBs, with the purpose of opening $\mathrm{BBB}$ and easier tumor perfusion. The FUS sonication was followed by magnetic resonance imaging (MRI) for SD-MBs visualization, simultaneously with magnetic targeting (MT) for increased drug delivery to the tumor site.

Although theranostic tools are very promising and versatile, future studies should be further focused on efficiency of tumor reduction and survival in glioblastoma animal models as well as treatment safety. These more extensive preclinical studies would justify applying this approach in future clinical treatments.

Similar strategy has been used in another study with thermo-responsive liposomes (68). Liposomes were modified with gadolinium and rhodamine and could therefore be used for both ultrasound-mediated drug delivery as well as MRI and optical imaging. The group synthesized $t$ liposomes with different transition temperature $(\mathrm{Tt})$, the temperature at which liposomes undergoes gel-to-liquid crystalline phase transition. One thermoresponsive liposome, The New Thermosensitive liposome (NLP), was designed with a Gadolinium-DOTA lipid bilayer and a $\mathrm{Tt}$ of $42^{\circ} \mathrm{C}$. The second thermosensitive liposome The Conventional liposome (CLP), was designed with GdDTPA-BSA lipid and a $\mathrm{Tt}$ of $60^{\circ} \mathrm{C}(68,69)$. At determined Tt the transmembrane permeability of liposomal complex was increased.

Using light microscopy to show that the designed liposomes accumulated in the flank of a murine glioma model, they further modified the liposome surface with biotin and rhodamine, which tightly binds to Gli36 glioma cells expressing biotin acceptor peptide (BAP). Significantly higher accumulation of liposomes was observed in BAP-expressing tumors, indicating efficient tumor targeting and imaging capabilities using MRI.

Since the designed liposome are thermo-responsive they have a potential to be targeted to the tumor tissue and release the drug when external mild heat is applied. To further demonstrate drug delivery potential, additional experiments including drug encapsulation and determination of stability of liposomes in plasma and efficacy in orthotopic glioma model are necessary to advance this technology to its full potential.

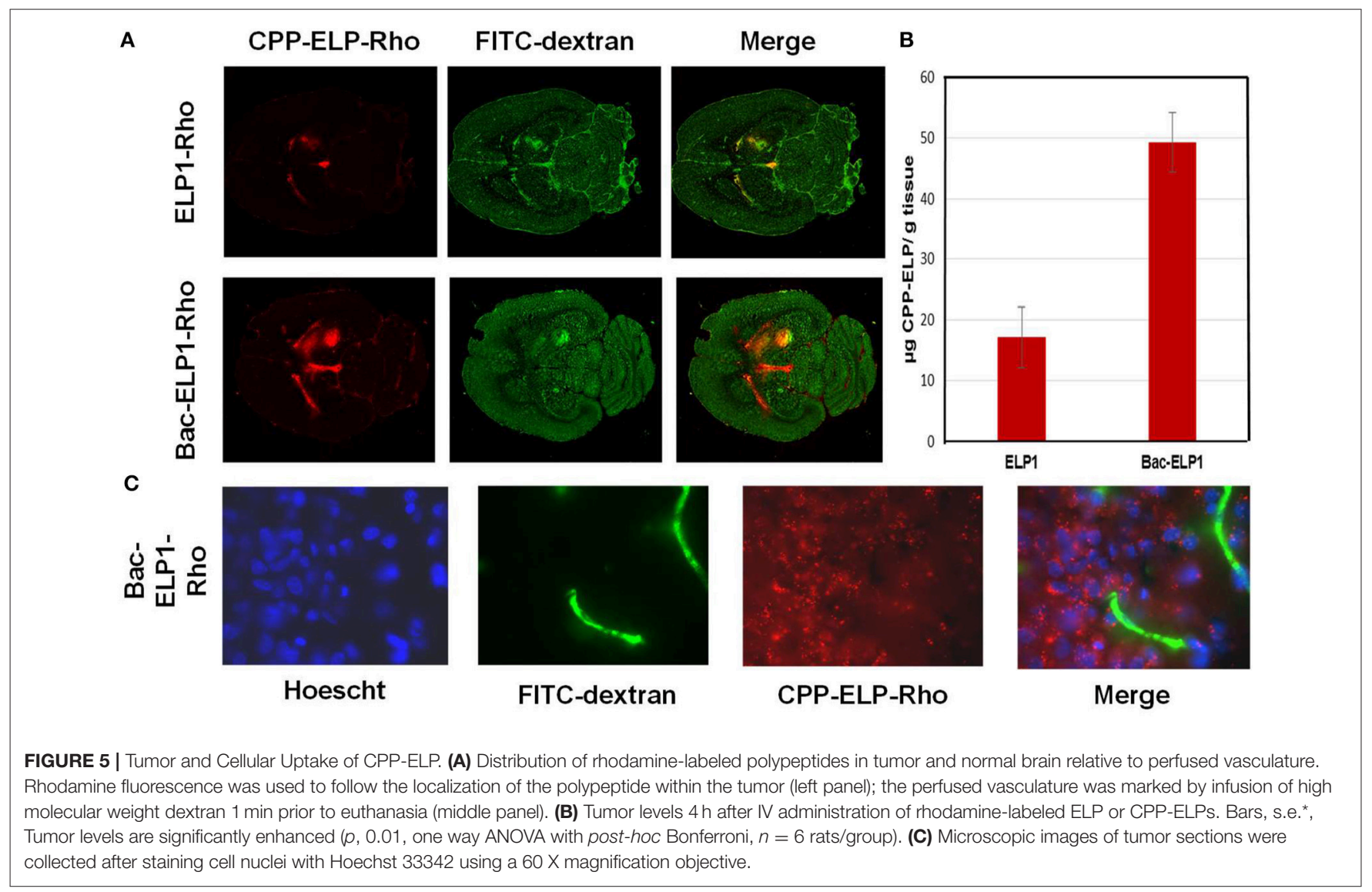




\section{Temperature-Responsive Drug Carriers}

Thermo-responsive drug delivery carriers are one of the most investigated stimuli-responsive strategies for targeted, stimuli-responsive drug delivery. Temperature-responsive drug carriers undergo phase transition and rapid change in their physical property at certain temperatures; lower critical solution temperature (LCST). Below LCST, drug carriers are soluble but upon heating they become insoluble, which may increase drug carrier accumulation or trigger drug release in the heated tumor area. Moreover, LCST may be modulated by incorporation of hydrophilic or hydrophobic monomers to achieve LCST temperature corresponding to mild hyperthermia $\left(37-42^{\circ} \mathrm{C}\right)$. This temperature range is desirable, since it is higher than normal temperature, but lower than temperatures which may damage healthy tissue. Furthermore, mild hyperthermia can be effectively localized and contained within the tumor site without spilling into adjacent normal tissue. As tumors have a defective vascular architecture and impaired lymphatic drainage, the application of mild heat results in the preferential retention and increased concentration of drugs. Additionally, hyperthermia is a mature clinical modality currently used in clinics, rendering the methods, and techniques necessary to employ targeting of thermally sensitive polypeptides available in the clinical setting. Further hyperthermia increases blood flow, resulting in an increased permeability of the tumor, as compared to normal vasculature and hyperthermia increases tumor vasculature pore size, enhancing extravasation of macromolecules $(70,71)$ and cellular uptake $(72,73)$.

\section{Elastin-Like Polypeptides}

One class of thermo-responsive drug carriers, which was developed in our lab, is based on the thermally responsive

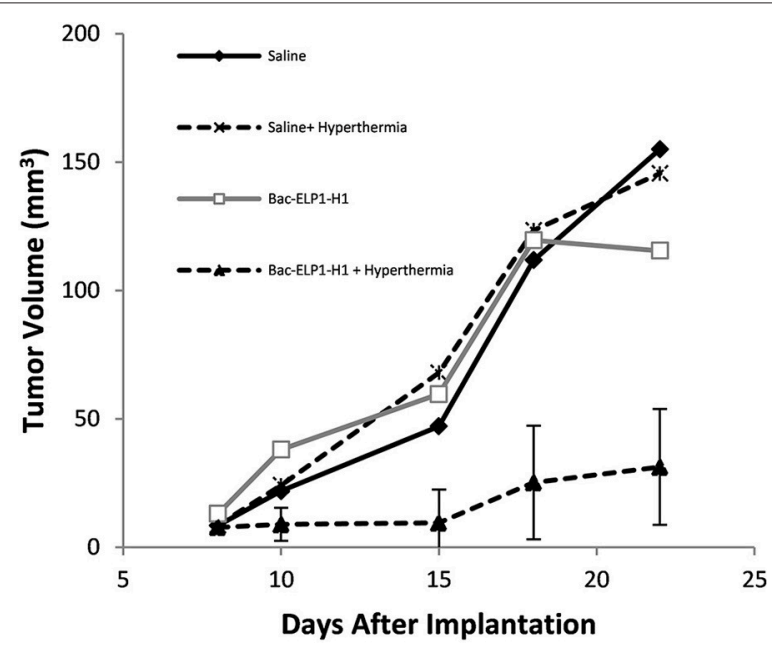

FIGURE 6 | Inhibition of Glioma Progression by the Thermally Targeted c-Myc Inhibitory Polypeptide. Sprague Dawley rats bearing intracerebral C6 tumors were treated with 4 daily IV injections of the Thermally Targeted c-Myc Inhibitory Polypeptide, with MRI monitoring of tumor volume. Average tumor volume for each treatment group. $n=6-8$ animals per group; *, Tumor volume was significantly reduced compared to control tumors (one way ANOVA, post hoc Bonferroni). biopolymer elastin-like polypeptide (ELP). An ELP, soluble at physiological temperatures, undergoes a phase transition and aggregates in response to an externally applied mild hyperthermia $\left(40-41^{\circ} \mathrm{C}\right)$. Our ELP's coding sequence was modified by adding a cell penetrating peptide (CPP) Bac, to enhance polypeptide delivery across the blood brain barrier (BBB) and to facilitate cell entry. Also added was a peptide, derived from helix $1(\mathrm{H} 1)$ of the helix-loop-helix region of c-Myc (H1-S6A, F8A), to inhibit c-Myc transcriptional activity and cell proliferation. Schematic of the ELP based drug delivery vector was presented in Figure 3.

ELPs are genetically engineered biopolymers that, in addition to all the benefits of macromolecular drug delivery systems, provide a number of additional advantages: (1) ELPs are thermally responsive biopolymers which undergo a sharp $\left(2-3^{\circ} \mathrm{C}\right.$ range) phase transition, leading to desolvation and aggregation of the biopolymer when the temperature is raised above their $\mathrm{Tt}(74,75)$, rendering them suitable for thermal targeting; (2) ELPs are genetically encoded, providing control over the ELP sequence and molecular weight (MW) to an extent impossible with synthetic polymer analogs which allows ELP molecular weights to be precisely specified, resulting in monodisperse polymers, a feat difficult to achieve with synthetic polymers; (3) ELP composition can be encoded at the gene level, allowing an ELP sequence to be modified by adding cell penetrating peptides, and therapeutic peptides. These targeting peptides can then be used to define tissue distribution, tumor penetration, and sub-cellular uptake/localization. Together, these properties make ELPs a promising class of biopolymers for targeted drug delivery.

\section{Thermally targeting increases delivery of CPP-ELP1-H1 to intracerebral gliomas}

We tested the ability of the CPP-ELP1-H1 polypeptide to be thermally targeted to tumors. Rats bearing intracerebral tumors were injected IV with Alexa750-labeled BacELP1-H1. Tumors were heated using the described thermal cycling protocol (54), and tumor deposition was determined by ex vivo imaging of rat brains $4 \mathrm{~h}$ after injection using an IVIS Spectrum animal imager. Polypeptide accumulation in tumors occurred at a high level relative to adjacent normal brain (Figure 4A). Moreover, tumor polypeptide levels noticeably increased when BacELP1-H1 treatment was combined with tumor hyperthermia. Quantitation of tumor fluorescence intensity revealed that thermal targeting increased Bac-ELP1-H1-Alexa750 tumor accumulation by 3.3-fold (Figure 4B, $p=0.0004$, Student's $t$ test).

\section{CPP-ELP1-H1 can penetrate the BBB and enter GBM cells}

A major barrier to GBM treatment is posed by the BBB, which any proposed therapeutic must penetrate. To assess the ability of CPP peptides to do so, and to determine their capacity to mediate ELP drug carrier delivery into C6 brain tumors, rats bearing intracranial C6 tumors were IV injected with Rhodamine-labeled CPP-ELP1 or an ELP1 control. At $4 \mathrm{~h}$ after injection, a $500 \mathrm{kDa}$ FITC-dextran was injected to mark perfused vasculature, the animal sacrificed, and the 
brain removed, frozen, and sectioned (Figure 5A). Slides were scanned with a ScanArray Express slide scanner (Perkin Elmer), with fluorescence intensity determined using Image J software. Tumor intensity, expressed relative to plasma concentration at time zero $\left(\mathrm{RFU} / \mathrm{C}_{0}\right)$, was averaged for all animals. ELP passive accumulation in $\mathrm{C} 6$ tumors was higher than in normal brain tissue; however, adding a CPP greatly enhanced tumor fluorescence relative to unmodified ELP. Comparing CPPELP-Rhodamine fluorescence with FITC-dextran fluorescence (Figure 5B) showed: (1) slightly greater enrichment of perfused vessels in tumors than in normal brain, and (2) significantly greater polypeptide accumulation in the tumor than in normal neural tissue. Microscopic examination of tumor sections showed the presence of CPP-delivered ELP in the blood vessels, extravascular space, and within tumor cells (Figure 5C). These data indicate the ELP polypeptide's passive accumulation in brain tumors in this rat model, as well as the enhancement conferred for total tumor levels and deposition throughout the tumor, relative to a non-CPP containing control, by using the $\mathrm{CPP}$.

\section{Reduction of intracranial C6 tumor proliferation by Bac-ELP-H1}

After demonstrating that CPP-ELP-H1 can enter C6 tumors in brain, the construct's effects on tumor progression and animal survival were evaluated.

Rats bearing intracerebral C6 tumors were treated daily for 4 days beginning on day 9 after implantation. The CPP-ELP1$\mathrm{H} 1$ polypeptide, or control polypeptides lacking the $\mathrm{H} 1$ peptide (Bac-ELP1) or utilizing the non-thermally responsive version of ELP (Bac-ELP2-H1), was injected IV. In the hyperthermia groups, hyperthermia was applied to the tumor site using a thermal cycling protocol immediately after each injection. Tumor progression was monitored using multi-slice $3 \mathrm{D}$ T1 trans-axial

Imaging with a gadolinium-based contrast on days 10, 15, 18, and 22. As shown in Figure 5, the C6 tumors progressed rapidly in all treatment groups except those in the Bac-ELP1H1 + hyperthermia group; in this group, tumor volumes were $80 \%$ smaller, with a mean volume of $31 \mathrm{~mm}^{3}$ ( $p=0.004$, one-way ANOVA, Figure 6).

Control polypeptides without H1 peptide (CPP-ELP1) had no effect on tumor reduction, while the non-thermally responsive ELP (CPP-ELP2-H1) resulted in a 30\% tumor reduction (data not shown).

These results are significant, since they demonstrate that it is feasible to increase brain tumor uptake of thermally responsive ELP drug carriers with focused hyperthermia, but also thermal targeting of the Bac-ELP1-H1 polypeptide to the tumors resulted in significant delayed onset of neurological deficits, $80 \%$ tumor volume reduction, and at least doubled survival.

While these results demonstrate that use of ELP to thermally target the H1 peptide, similar approach may be used to apply ELP technology for delivery of other therapeutic peptides for glioma. Future studies should expand this testing into other GBM models, including mouse orthotopic xenografts of human glioblastoma cells.

\section{CONCLUSION AND FUTURE PERSPECTIVES}

The current treatment of glioblastoma is particularly challenging not only because of the delivery of therapeutics to the brain, but also because of the tumor heterogeneity, aggressiveness, and recurrence. Although prognosis for the glioblastoma patients remains poor, recent developments in drug delivery approaches provide hope for the successful treatment of glioblastoma. This article reviewed recent progress and potential of macromolecular drug carriers. Macromolecular carriers increase efficacy, stability and plasma half-life of anticancer drugs, and reduce toxicity to healthy tissues. Tumor targeting of macromolecular carriers mostly rely on the passive tumor targeting via the enhanced permeability and retention effect. However, in addition to passive targeting, numerous macromolecular carriers have been developed to deliver and/or release drugs in response to internal or external stimuli, including $\mathrm{pH}$, enzymes, redox potential, magnetic field, ultrasound, and temperature. These stimuli-responsive macromolecules provide active targeting for anticancer drugs and further improve delivery of the drugs specifically to the tumor tissue. However, despite the progress which has been achieved in development of macromolecular carriers, some challenges for their successful clinical application remain.

Beside heterogeneity of tumors across the patients and tumor types, such as difference in $\mathrm{pH}$ and expression of specific enzymes, both of which may influence drug delivery in response to internal stimuli, there is also the issue of non-specific biodistribution of macromolecular carriers in other organs, such as liver and kidneys. Furthermore, complex design of some of the carriers and difficulties in scaling up their production may present further limitations in clinical applications. Due to these reasons there are only a limited number of macromolecular carriers presently used in clinics. Substantial progress may be possible if the research efforts are also focused not only on developing efficient macromolecular carriers, but also on development and selection of clinically-relevant animal models and assays which can more precisely predict their potential toxic effects.

\section{AUTHOR CONTRIBUTIONS}

DR wrote the initial drafts of the manuscript. SD and JR wrote subsequent drafts of the manuscripts, and produced figures. All authors reviewed and approved the final submitted manuscript.

\section{FUNDING}

National Science Foundation PFI:AIR-TT; Award Number:1640519.

\section{ACKNOWLEDGMENTS}

We would like to thank Dr. Bettye Sue Hennington for manuscript editing. 


\section{REFERENCES}

1. Ryu JS, Kuna M, Raucher D. Penetrating the cell membrane, thermal targeting and novel anticancer drugs: the development of thermally targeted, elastin-like polypeptide cancer therapeutics. Ther Deliv. (2014) 5:429-45. doi: $10.4155 /$ tde. 14.14

2. Bazak R, Houri M, El Achy S, Kamel S, Refaat T. Cancer active targeting by nanoparticles: a comprehensive review of literature. J Cancer Res Clin Oncol. (2015) 141:769-84. doi: 10.1007/s00432-014-1767-3

3. Rosenblum D, Joshi N, Tao W, Karp JM, Peer D. Progress and challenges towards targeted delivery of cancer therapeutics. Nat Commun. (2018) 9:1410. doi: 10.1038/s41467-018-03705-y

4. Ryu JS, Raucher D. Elastin-like polypeptide for improved drug delivery for anticancer therapy: preclinical studies and future applications. Expert Opin Drug Deliv. (2015) 12:653-67. doi: 10.1517/17425247.2015.974546

5. Kalim M, Chen J, Wang S, Lin C, Ullah S, Liang K, et al. Intracellular trafficking of new anticancer therapeutics: antibody-drug conjugates. Drug Des Devel Ther. (2017) 11:2265-76. doi: 10.2147/DDDT.S135571

6. Lewis Phillips GD, Li G, Dugger DL, Crocker LM, Parsons KL, Mai E, et al. Targeting HER2-positive breast cancer with trastuzumab-DM1, an antibody-cytotoxic drug conjugate. Cancer Res. (2008) 68:9280-90. doi: 10.1158/0008-5472.CAN-08-1776

7. Diessner J, Bruttel V, Stein RG, Horn E, Hausler SF, Dietl J, et al. Targeting of preexisting and induced breast cancer stem cells with trastuzumab and trastuzumab emtansine (T-DM1). Cell Death Dis. (2014) 5:e1149. doi: 10.1038/cddis.2014.115

8. Furnari FB, Fenton T, Bachoo RM, Mukasa A, Stommel JM, Stegh A, et al. Malignant astrocytic glioma: genetics, biology, and paths to treatment. Genes Dev. (2007) 21:2683-710. doi: 10.1101/gad.1596707

9. Yewale C, Baradia D, Vhora I, Patil S, Misra A. Epidermal growth factor receptor targeting in cancer: a review of trends and strategies. Biomaterials (2013) 34:8690-707. doi: 10.1016/j.biomaterials.2013.07.100

10. Jamali Z, Khoobi M, Hejazi SM, Eivazi N, Abdolahpour S, Imanparast F, et al. Evaluation of targeted curcumin (CUR) loaded PLGA nanoparticles for in vitro photodynamic therapy on human glioblastoma cell line. Photodiagnosis Photodyn Ther. (2018) 23:190-201. doi: 10.1016/j.pdpdt.2018.06.026

11. Kuo YC, Lee CH. Dual targeting of solid lipid nanoparticles grafted with 83$14 \mathrm{MAb}$ and anti-EGF receptor for malignant brain tumor therapy. Life Sci. (2016) 146:222-31. doi: 10.1016/j.lfs.2016.01.025

12. Ramalho MJ, Sevin E, Gosselet F, Lima J, Coelho MAN, Loureiro JA, et al. Receptor-mediated PLGA nanoparticles for glioblastoma multiforme treatment. Int J Pharm. (2018) 545:84-92. doi: 10.1016/j.ijpharm.2018.04.062

13. Li C, Tan J, Chang J, Li W, Liu Z, Li N, et al. Radioiodine-labeled anti-epidermal growth factor receptor binding bovine serum albuminpolycaprolactone for targeting imaging of glioblastoma. Oncol Rep. (2017) 38:2919-26. doi: 10.3892/or.2017.5937

14. Wadajkar AS, Dancy JG, Roberts NB, Connolly NP, Strickland DK, Winkles JA, et al. Decreased non-specific adhesivity, receptor targeted (DART) nanoparticles exhibit improved dispersion, cellular uptake, and tumor retention in invasive gliomas. J Control Release (2017) 267:144-53. doi: 10.1016/j.jconrel.2017.09.006

15. Nilewski LG, Singh M, Baskin DS, Tour JM, Sharpe MA. Transfer of dyes and drugs into cells using EGFR-targeted nanosyringes. ACS Chem Neurosci. (2018) 9:107-17. doi: 10.1021/acschemneuro.7b00138

16. Prabhu S, Goda JS, Mutalik S, Mohanty BS, Chaudhari P, Rai S, et al. A polymeric temozolomide nanocomposite against orthotopic glioblastoma xenograft: tumor-specific homing directed by nestin. Nanoscale (2017) 9:10919-32. doi: 10.1039/C7NR00305F

17. Tivnan A, Heilinger T, Ramsey JM, O'Connor G, Pokorny JL, Sarkaria JN, et al. Anti-GD2-ch14.18/CHO coated nanoparticles mediate glioblastoma (GBM)-specific delivery of the aromatase inhibitor, Letrozole, reducing proliferation, migration, and chemoresistance in patient-derived GBM tumor cells. Oncotarget (2017) 8:16605-20. doi: 10.18632/oncotarget.15073

18. Sarisozen C, Dhokai S, Tsikudo EG, Luther E, Rachman IM, Torchilin VP. Nanomedicine based curcumin and doxorubicin combination treatment of glioblastoma with scFv-targeted micelles: in vitro evaluation on $2 \mathrm{D}$ and 3D tumor models. Eur J Pharm Biopharm. (2016) 108:54-67. doi: $10.1016 /$ j.ejpb.2016.08.013
19. Khutornenko AA, Gerasimov VM, Sakharov DA. Preparation of viscuminferromagnetic particles conjugate and study of its internalization by human glioblastoma A172 cells. Bull Exp Biol Med. (2016) 160:823-6. doi: 10.1007/s10517-016-3319-0

20. MacDiarmid JA, Langova V, Bailey D, Pattison ST, Pattison SL, Christensen $\mathrm{N}$, et al. Targeted doxorubicin delivery to brain tumors via minicells: proof of principle using dogs with spontaneously occurring tumors as a model. PLoS ONE (2016) 11:e0151832. doi: 10.1371/journal.pone.0151832

21. Shah R, Petersburg J, Gangar AC, Fegan A, Wagner CR, Kumarapperuma SC. In vivo evaluation of site-specifically PEGylated chemically selfassembled protein nanostructures. Mol Pharm. (2016) 13:2193-203. doi: 10.1021/acs.molpharmaceut.6b00110

22. Wei Y, Zhou F, Zhang D, Chen Q, Xing D. A graphene oxide based smart drug delivery system for tumor mitochondria-targeting photodynamic therapy. Nanoscale (2016) 8:3530-8. doi: 10.1039/C5NR07785K

23. Kuo YC, Wang IH. Enhanced delivery of etoposide across the blood-brain barrier to restrain brain tumor growth using melanotransferrin antibodyand tamoxifen-conjugated solid lipid nanoparticles. J Drug Target (2016) 24:645-54. doi: 10.3109/1061186X.2015.1132223

24. Kuo YC, Chao IW. Conjugation of melanotransferrin antibody on solid lipid nanoparticles for mediating brain cancer malignancy. Biotechnol Prog. (2016) 32:480-90. doi: 10.1002/btpr.2214

25. Shevtsov MA, Nikolaev BP, Ryzhov VA, Yakovleva LY, Marchenko YY, Parr MA, et al. Ionizing radiation improves glioma-specific targeting of superparamagnetic iron oxide nanoparticles conjugated with cmHsp70.1 monoclonal antibodies (SPION-cmHsp70.1). Nanoscale (2015) 7, 20652-64. doi: 10.1039/C5NR06521F

26. Abakumova T, Abakumov M, Shein S, Chelushkin P, Bychkov D, Mukhin V, et al. Connexin 43-targeted T1 contrast agent for MRI diagnosis of glioma. Contrast Media Mol Imaging (2016) 11:15-23. doi: 10.1002/cmmi.1653

27. Bouras A, Kaluzova M, Hadjipanayis CG. Radiosensitivity enhancement of radioresistant glioblastoma by epidermal growth factor receptor antibodyconjugated iron-oxide nanoparticles. J Neurooncol. (2015) 124:13-22. doi: $10.1007 /$ s11060-015-1807-0

28. Kaluzova M, Bouras A, Machaidze R, Hadjipanayis CG. Targeted therapy of glioblastoma stem-like cells and tumor non-stem cells using cetuximabconjugated iron-oxide nanoparticles. Oncotarget (2015) 6:8788-806. doi: 10.18632/oncotarget. 3554

29. Abakumov MA, Nukolova NV, Sokolsky-Papkov M, Shein SA, Sandalova TO, Vishwasrao HM, et al. VEGF-targeted magnetic nanoparticles for MRI visualization of brain tumor. Nanomedicine (2015) 11:825-33. doi: 10.1016/j.nano.2014.12.011

30. Schneider CS, Perez JG, Cheng E, Zhang C, Mastorakos P, Hanes J, et al. Minimizing the non-specific binding of nanoparticles to the brain enables active targeting of Fn14-positive glioblastoma cells. Biomaterials (2015) 42:42-51. doi: 10.1016/j.biomaterials.2014.11.054

31. Nukolova NV, Baklaushev VP, Abakumova TO, Mel'nikov PA, Abakumov MA, Yusubalieva GM, et al. Targeted delivery of cisplatin by small es, Cyrilliconnexin 43 vector nanogels to the focus of experimental glioma C6. Bull Exp Biol Med. (2014) 157:524-9. doi: 10.1007/s10517-0142606-x

32. Crisp JL, Savariar EN, Glasgow HL, Ellies LG, Whitney MA, Tsien RY. Dual targeting of integrin alphavbeta3 and matrix metalloproteinase-2 for optical imaging of tumors and chemotherapeutic delivery. Mol Cancer Ther. (2014) 13:1514-25. doi: 10.1158/1535-7163.MCT-13-1067

33. Baklaushev VP, Nukolova NN, Khalansky AS, Gurina OI, Yusubalieva GM, Grinenko NP, et al. Treatment of glioma by cisplatin-loaded nanogels conjugated with monoclonal antibodies against $\mathrm{Cx} 43$ and BSAT1. Drug Deliv. (2015) 22:276-85. doi: 10.3109/10717544.2013.876460

34. Mahmud H, Kasai T, Khayrani AC, Asakura M, Oo AKK, Du J, et al. Targeting glioblastoma cells expressing CD44 with liposomes encapsulating doxorubicin and displaying chlorotoxin-IgG Fc fusion protein. Int J Mol Sci. (2018) 19:E659. doi: 10.3390/ijms19030659

35. Kim JS, Shin DH, Kim JS. Dual-targeting immunoliposomes using angiopep2 and CD133 antibody for glioblastoma stem cells. J Control Release (2018) 269:245-57. doi: 10.1016/j.jconrel.2017.11.026

36. Sehedic D, Chourpa I, Tetaud C, Griveau A, Loussouarn C, Avril S, et al. Locoregional confinement and major clinical benefit of (188)re-loaded 
CXCR4-targeted nanocarriers in an orthotopic human to mouse model of glioblastoma. Theranostics (2017) 7:4517-36. doi: 10.7150/thno.19403

37. Bhunia S, Vangala V, Bhattacharya D, Ravuri HG, Kuncha M, Chakravarty $\mathrm{S}$, et al. Large amino acid transporter 1 selective liposomes of 1-DOPA functionalized amphiphile for combating glioblastoma. Mol Pharm. (2017) 14:3834-47. doi: 10.1021/acs.molpharmaceut.7b00569

38. Zhou JE, Yu J, Gao L, Sun L, Peng T, Wang J, et al. iNGR-modified liposomes for tumor vascular targeting and tumor tissue penetrating delivery in the treatment of glioblastoma. Mol Pharm. (2017) 14:1811-20. doi: 10.1021/acs.molpharmaceut.7b00101

39. Shein SA, Kuznetsov II, Abakumova TO, Chelushkin PS, Melnikov PA, Korchagina AA, et al. VEGF- and VEGFR2-targeted liposomes for cisplatin delivery to glioma cells. Mol Pharm. (2016) 13:3712-23. doi: 10.1021/acs.molpharmaceut.6b00519

40. Shin DH, Lee SJ, Kim JS, Ryu JH, Kim JS. Synergistic effect of immunoliposomal gemcitabine and bevacizumab in glioblastoma stem cell-targeted therapy. J Biomed Nanotechnol. (2015) 11:1989-2002. doi: 10.1166/jbn.2015.2146

41. Kim SS, Rait A, Kim E, DeMarco J, Pirollo KF, Chang EH. Encapsulation of temozolomide in a tumor-targeting nanocomplex enhances anti-cancer efficacy and reduces toxicity in a mouse model of glioblastoma. Cancer Lett. (2015) 369:250-8. doi: 10.1016/j.canlet.2015.08.022

42. Mortensen JH, Jeppesen M, Pilgaard L, Agger R, Duroux M, Zachar $\mathrm{V}$, et al. Targeted antiepidermal growth factor receptor (cetuximab) immunoliposomes enhance cellular uptake in vitro and exhibit increased accumulation in an intracranial model of glioblastoma multiforme. J Drug Deliv. (2013) 2013:209205. doi: 10.1155/2013/209205

43. Bao X, Pastan I, Bigner DD, Chandramohan V. EGFR/EGFRvIII-targeted immunotoxin therapy for the treatment of glioblastomas via convectionenhanced delivery. Receptors Clin Investig. 3:e1430. doi: 10.14800/rci.1430

44. Nielsen CF, van Putten SM, Lund IK, Melander MC, Norregaard $\mathrm{KS}$, Jurgensen $\mathrm{HJ}$, et al. The collagen receptor uPARAP/Endo180 as a novel target for antibody-drug conjugate mediated treatment of mesenchymal and leukemic cancers. Oncotarget (2017) 8:44605-24. doi: 10.18632 /oncotarget.17883

45. Shoji T, Saito R, Chonan M, Shibahara I, Sato A, Kanamori M, et al. Local convection-enhanced delivery of an anti-CD40 agonistic monoclonal antibody induces antitumor effects in mouse glioma models. Neuro Oncol. (2016) 18:1120-8. doi: 10.1093/neuonc/now023

46. Langone P, Debata PR, Inigo Jdel R, Dolai S, Mukherjee S, Halat P, et al. Coupling to a glioblastoma-directed antibody potentiates antitumor activity of curcumin. Int J Cancer (2014) 135:710-9. doi: 10.1002/ijc. 28555

47. Calzolari A, Larocca LM, Deaglio S, Finisguerra V, Boe A, Raggi C, et al. Transferrin receptor 2 is frequently and highly expressed in glioblastomas. Transl Oncol. (2010) 3:123-34. doi: 10.1593/tlo.09274

48. Roberts RL, Fine RE, Sandra A. Receptor-mediated endocytosis of transferrin at the blood-brain barrier. J Cell Sci. (1993) 104:521-32.

49. Voth B, Nagasawa DT, Pelargos PE, Chung LK, Ung N, Gopen Q, et al. Transferrin receptors and glioblastoma multiforme: current findings and potential for treatment. J Clin Neurosci. (2015) 22:1071-6. doi: 10.1016/j.jocn.2015.02.002

50. Zhang X, Lin Y, Gillies RJ. Tumor pH and its measurement. J Nucl Med. (2010) 51:1167-70. doi: 10.2967/jnumed.109.068981

51. Kanamala M, Wilson WR, Yang M, Palmer BD, Wu Z. Mechanisms and biomaterials in $\mathrm{pH}$-responsive tumour targeted drug delivery: a review. Biomaterials (2016) 85:152-67. doi: 10.1016/j.biomaterials.2016.01.061

52. Miller K, Dixit S, Bredlau AL, Moore A, McKinnon E, Broome AM. Delivery of a drug cache to glioma cells overexpressing platelet-derived growth factor receptor using lipid nanocarriers. Nanomedicine (Lond) (2016) 11:581-95. doi: $10.2217 / \mathrm{nnm} .15 .218$

53. Marrero L, Wyczechowska D, Musto AE, Wilk A, Vashistha H, Zapata A, et al. Therapeutic efficacy of aldoxorubicin in an intracranial xenograft mouse model of human glioblastoma. Neoplasia (2014) 16:874-82. doi: 10.1016/j.neo.2014.08.015

54. Bidwell GL III, Perkins E, Hughes J, Khan M, James JR, Raucher D. Thermally targeted delivery of a c-Myc inhibitory polypeptide inhibits tumor progression and extends survival in a rat glioma model. PLoS One (2013) 8:e55104. doi: 10.1371/journal.pone.0055104

55. Zhao Y, Ren W, Zhong T, Zhang S, Huang D, Guo Y, et al. Tumor-specific pHresponsive peptide-modified $\mathrm{pH}$-sensitive liposomes containing doxorubicin for enhancing glioma targeting and anti-tumor activity. J Control Release (2016) 222:56-66. doi: 10.1016/j.jconrel.2015.12.006

56. Fan CH, Cheng YH, Ting CY, Ho YJ, Hsu PH, Liu HL, et al. Ultrasound/magnetic targeting with SPIO-DOX-Microbubble complex for image-guided drug delivery in brain tumors. Theranostics (2016) 6:1542-56. doi: $10.7150 /$ thno. 15297

57. Stephen ZR, Kievit FM, Veiseh O, Chiarelli PA, Fang C, Wang K, et al. Redox-responsive magnetic nanoparticle for targeted convection-enhanced delivery of O6-benzylguanine to brain tumors. ACS Nano (2014) 8:10383-95. doi: $10.1021 / \mathrm{nn} 503735 \mathrm{w}$

58. Jiang Y, Yang W, Zhang J, Meng F, Zhong Z. Protein toxin chaperoned by LRP-1-targeted virus-mimicking vesicles induces high-efficiency glioblastoma therapy in vivo. Adv Mater. (2018) 30:e1800316. doi: 10.1002/adma.201800316

59. Ruan C, Liu L, Lu Y, Zhang Y, He X, Chen X, et al. Substance P-modified human serum albumin nanoparticles loaded with paclitaxel for targeted therapy of glioma. Acta Pharm Sin B (2018) 8:85-96. doi: 10.1016/j.apsb.2017.09.008

60. Mohanty S, Chen Z, Li K, Morais GR, Klockow J, Yerneni K, et al. A novel theranostic strategy for MMP-14-expressing glioblastomas impacts survival. Mol Cancer Ther. (2017) 16:1909-21. doi: 10.1158/1535-7163.MCT-17-0022

61. Gu G, Xia H, Hu Q, Liu Z, Jiang M, Kang T, et al. PEG-co-PCL nanoparticles modified with MMP-2/9 activatable low molecular weight protamine for enhanced targeted glioblastoma therapy. Biomaterials (2013) 34:196-208. doi: 10.1016/j.biomaterials.2012.09.044

62. Sosa V, Moline T, Somoza R, Paciucci R, Kondoh H, LLeonart ME, et al. Oxidative stress and cancer: an overview. Ageing Res Rev. (2013) 12:376-90. doi: 10.1016/j.arr.2012.10.004

63. Cheng R, Feng F, Meng F, Deng C, Feijen J, Zhong Z. Glutathione-responsive nano-vehicles as a promising platform for targeted intracellular drug and gene delivery. J Control Release (2011) 152:2-12. doi: 10.1016/j.jconrel.2011. 01.030

64. Demeule M, Currie JC, Bertrand Y, Che C, Nguyen T, Regina A, et al. Involvement of the low-density lipoprotein receptor-related protein in the transcytosis of the brain delivery vector angiopep-2. J Neurochem. (2008) 106:1534-44. doi: 10.1111/j.1471-4159.2008.05492.x

65. Demeule M, Beaudet N, Regina A, Besserer-Offroy E, Murza A, Tetreault $\mathrm{P}$, et al. Conjugation of a brain-penetrant peptide with neurotensin provides antinociceptive properties. J Clin Invest. (2014) 124:1199-213. doi: 10.1172/JCI70647

66. Wei KC, Chu PC, Wang HY, Huang CY, Chen PY, Tsai HC, et al. Focused ultrasound-induced blood-brain barrier opening to enhance temozolomide delivery for glioblastoma treatment: a preclinical study. PLoS ONE (2013) 8:e58995. doi: 10.1371/journal.pone.0058995

67. Kovacs Z, Werner B, Rassi A, Sass JO, Martin-Fiori E, Bernasconi M. Prolonged survival upon ultrasound-enhanced doxorubicin delivery in two syngenic glioblastoma mouse models. J Control Release (2014) 187:74-82. doi: 10.1016/j.jconrel.2014.05.033

68. Kuijten MMP, Hannah Degeling M, Chen JW, Wojtkiewicz G, Waterman $\mathrm{P}$, Weissleder $\mathrm{R}$, et al. Multimodal targeted high relaxivity thermosensitive liposome for in vivo imaging. Sci Rep. (2015) 5:17220. doi: 10.1038/srep17220

69. Strijkers GJ, Kluza E, Van Tilborg GA, van der Schaft DW, Griffioen AW, Mulder WJ, et al. Paramagnetic and fluorescent liposomes for target-specific imaging and therapy of tumor angiogenesis. Angiogenesis (2010) 13:161-73. doi: 10.1007/s10456-010-9165-1

70. Issels RD. Regional hyperthermia combined with systemic chemotherapy of locally advanced sarcomas: preclinical aspects and clinical results. Recent Results Cancer Res (1995) 138:81-90. doi: 10.1007/978-3-642-78768-3_10

71. Feyerabend T, Steeves R, Wiedemann GJ, Richter E, Robins HI. Rationale and clinical status of local hyperthermia, radiation, and chemotherapy in locally advanced malignancies. Anticancer Res. (1997) 17:2895-7.

72. Raucher D, Chilkoti A. Enhanced uptake of a thermally responsive polypeptide by tumor cells in response to its hyperthermia-mediated phase transition. Cancer Res. (2001) 61:7163-70. 
73. Massodi I, Raucher D. A thermally responsive Tat-elastinlike polypeptide fusion protein induces membrane leakage, apoptosis, and cell death in human breast cancer cells. $J$ Drug Target. (2007) 15:611-22. doi: 10.1080/106118607015 02780

74. Urry DW, Trapane TL, Prasad KU. Phase-structure transitions of the elastin polypentapeptide-water system within the framework of composition-temperature studies. Biopolymers (1985) 24:2345-56. doi: 10.1002/bip.360241212

75. Urry DW, Luan C-H, Parker TM, Gowda DC, Prasad KU, Reid MC, et al. Temperature of polypeptide inverse temperature transition depends on mean residue hydrophobicity. J Am Chem Soc. (1991) 113:4346-8. doi: 10.1021/ja0001 $1 \mathrm{a} 057$
Conflict of Interest Statement: DR is the president of Thermally Targeted Therapeutics, Inc., Jackson, MS, USA.

The remaining authors declare that the research was conducted in the absence of any commercial or financial relationships that could be construed as a potential conflict of interest.

Copyright (C) 2018 Raucher, Dragojevic and Ryu. This is an open-access article distributed under the terms of the Creative Commons Attribution License (CC BY). The use, distribution or reproduction in other forums is permitted, provided the original author(s) and the copyright owner(s) are credited and that the original publication in this journal is cited, in accordance with accepted academic practice. No use, distribution or reproduction is permitted which does not comply with these terms. 